\title{
Post boşluğuna bağlayıcı uygulamalarının kendinden bağlanabilen rezin siman kullanılarak yapıştırılan fiber postların push-out bağlanma dayanımlarına etkileri
}

\author{
Tufan Can Okay, ${ }^{1}$ Mine Betül Üçtaşlı, ${ }^{2}$ \\ Hacer Deniz Arısu ${ }^{2 *}$ \\ 'izmir Kuzey Kamu Hastaneleri Birliği Genel Sekreterliği \\ Karşıyaka Ağız ve Diş Sağlığı Merkezi, Izmir, ${ }^{2}$ Diş Hastalıkları \\ ve Tedavisi Anabilim Dalı, Diş Hekimliği Fakültesi, Gazi \\ Üniversitesi, Ankara, Türkiye
}

\section{ÖZET}

AmAÇ: Aşırı kron harabiyeti gösteren endodontik tedavili dişlerin restorasyonunda kullanılan fiber post sisteminin post boşluğuna bağlayıcı rezin uygulanarak ya da uygulanmadan iki farklı kendinden bağlanabilen rezin simanla yapıştırııasının, push-out bağlanma dayanımı üzerine etkilerinin incelenmesidir.

Gereç Ve Yöntem: Çalışmada kullanılan çekilmiş 80 adet 1. küçük azı dişi kök kanal preparasyonları yapıldıktan sonra fiber postun (RelyX Fiber Post) yapıştırılmasında kullanılan materyallere göre 4 gruba ayrıldı. Grup 1 RelyX Unicem, Grup 2 RelyX Unicem + Adper Easy One, Grup 3 Clearfil SA Cement, Grup 4 Clearfil SA Cement + S3 Bond kullanılarak yapıştıııldı. Örnekler 24 saat ve 1 aylık sürelerde etüvde bekletildikten sonra fiber postun apikal, orta ve koronal bölgelerinden $1 \mathrm{~mm}$ 'lik horizontal 6 kesit alındı ve push-out bağlanma dayanımları değerlendirildi. Grupların karşılaştırılmasında tek yönlü varyans analizi ve Tukey HSD testleri, bekletme sürelerinin karşılaştırılmasında bağımsız değişkenler t-testi kullanıldı $(\alpha=0.05)$.

BULGULAR: Hem 24 saat hem de 1 aylık ölçüm sonuçlarına göre en yüksek bağlanma dayanım değerleri Rely $X$ Unicem + Adper Easy One grubunda gözlendi. En zayıf bağlantı 24 saat sonrasında postun apikal bölgesinden alınan kesitlerde görüldü, bunu orta ve koronal bölgeler izledi. 1. ay sonunda, apikal ve orta bölge kesitleri benzerlik gösterirken ( $p>0.05$ ), her iki bölge de koronal bölgeden daha düşük değerler gösterdi $(p<0.05)$. Apikal ve orta bölgelerde RelyX Unicem + Adper Easy One diğer gruplara göre daha yüksek bağlanma dayanımı değerleri gösterdi $(p<0.05)$.

Sonuç: Bu in vitro test koşulları altında post simantasyonunda, kendinden bağlanabilen rezin simanların uygun

E-posta:hacerdenizarisu@gmail.com bağlayıcılar ile birlikte kullanımının bağlanma dayanımını arttırdığı söylenebilir.

AnAhtar Kelimeler: Bağlantı ajanları, dentin; rezin simanları; post tekniği

KaynaK Göstermek İçin: Okay TC, Üçtaşlı MB, Deniz Arısu $H$. Post boşluğuna bağlayıcı uygulamalarının kendinden bağlanabilen rezin siman kullanılarak yapıştıılan fiber postların push-out bağlanma dayanımlarına etkileri. Acta Odontol Turc 2017;34(1):24-30

ЕрітӧR: Neşe Akal, Gazi Üniversitesi, Ankara, Türkiye

YAYIN HAKKI: @ 2017 Okay ve ark. Bu eserin yayın hakkı Creative Commons Attribution License ile ruhsatlandırılmıştır. Sınırsız kullanım, dağıtım ve her türlü ortamda çoğaltım, yazarlar ve kaynağın belirtilmesi kaydıyla serbesttir.

[Abstract in English is at the end of the manuscript]

\section{GiRiş}

Dişlerde meydana gelen travma, diş çürüğü, önceki restorasyonlardaki uyumsuzluklar, abrazyon, atrizyon, erozyon ve gelişim bozukluğu gibi faktörler ağız sağlığını ve genel sağlığı olumsuz yönde etkilemektedir. Endodontik tedaviler bu dişlerin ağızda tutulmasını sağlamakla birlikte, geniş çürük, kırık ve endodontik giriş kavitelerinden kaynaklanan madde kaybı, bu dişlerin restorasyonunu güçleştirmektedir. ${ }^{1}$ Koronal madde kaybı fazla olan bu tür dişler, vital dişlerle kıyaslandığında daha kırılgan özellik göstermektedirler. Huang ve ark. $^{2}$ bu kırılganlığı devital pulpanın nem eksikliği ile açıklarken, Sedgley ve Messer ${ }^{3}$ endodontik tedavi için giriş preparasyonu esnasında dişte oluşan madde kaybına bağlamaktadır. Endodontik tedavi görmüş ve aşırı madde kaybı olan dişlerin restorasyonları yapılırken endodontik post ve kor uygulanması en sık tercih edilen yöntemlerden biridir. ${ }^{4}$

Endodontik tedavi görmüş dişlerin restorasyonu için pek çok yöntem ve malzeme önerilmiştir. Metalik prefabrik ya da döküm postlar yıllardır kullanılmaktadır. Daha yakın geçmişte estetik beklentilerin artması sonucunda diş rengine uyumlu metal olmayan postlar üretilmiştir. ${ }^{5}$ 
Tablo 1. Çalışmada kullanılan materyaller ile ilgili bilgiler

\begin{tabular}{|c|c|c|c|}
\hline Materyal & Ürün adı & Üretici firma & İçerik \\
\hline $\begin{array}{l}\text { Kendinden } \\
\text { bağlanabilen rezin } \\
\text { siman }\end{array}$ & $\begin{array}{l}\text { RelyX Unicem Self-Adhesive Resin } \\
\text { Cement }\end{array}$ & $\begin{array}{l}\text { 3M Espe, St. Paul, } \\
\text { MN, ABD }\end{array}$ & $\begin{array}{c}\text { Toz/likit } \\
\text { Fosforik asit grupları içeren metakrilat monomerleri, } \\
\text { metakrilat monomerleri, silanlanmış doldurucular, alkalen } \\
\text { doldurucular }\end{array}$ \\
\hline $\begin{array}{l}\text { Kendinden } \\
\text { bağlanabilen rezin } \\
\text { siman }\end{array}$ & Clearfil SA Cement & $\begin{array}{l}\text { Kuraray, Osaka, } \\
\text { Japonya }\end{array}$ & $\begin{array}{l}\text { Pat/pat } \\
\text { MDP Hidrofobik aromatik dimetakrilat, hidrofobik alifatik } \\
\text { dimetakrilat, koloidal silika, baryum cam doldurucular }\end{array}$ \\
\hline $\begin{array}{l}\text { Kendinden } \\
\text { pürüzlendirmeli } \\
\text { bağlayıcı sistem }\end{array}$ & Adper Easy One & $\begin{array}{l}\text { 3M Espe, St. Paul, } \\
\text { MN, ABD }\end{array}$ & $\begin{array}{l}\text { HEMA, BisGMA, su, fosforik asit-metakrioksil-heksilester, } \\
\text { etanol, silanlanmış silika, HDDMA, akrilik ve itakonik asit } \\
\text { kopolimerleri, DMAEMA, fosfinoksit, kamforokinon }\end{array}$ \\
\hline $\begin{array}{l}\text { Kendinden } \\
\text { pürüzlendirmeli } \\
\text { bağlayıcı sistem }\end{array}$ & Clearfil S3 Bond & $\begin{array}{l}\text { Kuraray, Osaka } \\
\text { Japonya }\end{array}$ & $\begin{array}{l}\text { 10-MDP, HEMA, BisGMA, su, etanol, silanlanmış koloidal } \\
\text { silika, kamforokinon }\end{array}$ \\
\hline Fiber post & RelyX Fiber Post & $\begin{array}{l}\text { 3M Espe, Seefeld, } \\
\text { Almanya }\end{array}$ & Cam fiber \\
\hline
\end{tabular}

Post sistemlerinin başarısında mekanik dayanıklılıkları oldukça önemli bir rol oynamaktadır. Günümüzde endodontik tedavi görmüş dişlerin restorasyonunda dentinin elastiklik modülüne yakın daha az rijit materyallerin kullanımı tercih edilmektedir. Bununla birlikte kullanılan post materyali ile bir bütün sağlayacak, post boşluğunu tam olarak dolduracak bir yapıştırma simanına intiyaç duyulmaktadır. Bu tip postlar kompozit rezin esaslı yapıştırma simanları ile kullanıldığında homojen bir bütünlük sağlamakta, bu da postun kırılma riskini en aza indirmektedir. ${ }^{6}$ Kompozit esaslı rezin simanlar kullanılırken, kök kanalı içerisinde meydana gelen smear tabakanın bağlanmayı olumsuz etkilemesini önlemek için kök kanalı içerisinde smear tabakasını kaldıran ya da modifiye eden işlemlere gerek duyulmaktadır. Son yıllarda piyasaya sürülen kendinden bağlanabilen rezin simanlar, geleneksel simanların kullanım kolaylığı ve rezin simanların üstün estetik ve mekanik özelliklerini bir araya toplamaktadır. ${ }^{7}$ Bu simanların kullanımları sırasında kök dentinine herhangi bir ön işlem yapılmasına gerek yoktur. Bu da klinik basamak sayısının azalmasına, tedavi süresinin kısalmasına ve hekime bağlı teknik hataların azalmasına neden olmaktadır.

Bu çalışmanın amacı; aşırı kron harabiyeti gösteren endodontik tedavili dişlerin restorasyonunda kullanılan fiber post sisteminin, hem ışık hem de kimyasal yolla polimerize olan kompozit rezin esaslı kendinden bağlanabilen iki yapıştırma simanın hazırlanmış post boşluğundaki dentin yüzeylerine herhangi bir işlem uygulanmadan ve firma önerileri doğrultusunda tek basamaklı kendinden pürüzlendirmeli bağlayıcı sistemler kullanılarak uygulanmasının push-out bağlanma testine gösterdiği direncin karşılaştırılmasıdır.

Çalışmanın sıfır hipotezi, bağlayıcı sistem kullanımasının push out bağlanma direncini değiştirmeyeceğidir.

\section{GeREÇ VE YÖnTEM}

Çalışma için Ankara Üniversitesi Diş Hekimliği Fakültesi Klinik Araştırmalar Etik Kurulu'ndan onay alındı (Protokol no: 36290600-19).

Çalışmada periodontal veya ortodontik sebeplerle çekilmiş, kökleri tam olarak kapanmış, çatlak ya da kırık bulunmayan, kök çapları ve uzunlukları birbirine benzer olan (kök boyu 14-16 mm) 80 adet tek köklü alt birinci küçük azı dişi kullanıldı. Çalışmada kullanılan materyaller ile ilgili bilgiler Tablo 1'de verildi.

\section{Örneklerin hazırlanması}

Dişler örnekler hazırlanana kadar distile su içerisinde saklandı. Dişlerin kronları, mine sement sınırının $1 \mathrm{~mm}$ yukarısından su soğutması altında horizontal yönde kesilerek uzaklaştırıldı. Bir rond frez yardımıyla giriş kaviteleri hazırlandıktan sonra 10 numaralı K-tipi eğe kök ucundan görünecek kadar ilerletilip, tespit edilen uzunluktan $1 \mathrm{~mm}$ kısa olacak şekilde çalışma boyları tespit edildi. Kanallar Protaper (Dentsply, Maillefer, Ballaigues, İsviçre) Ni-Ti dönen alet serisi F3 numaralı eğe boyutunda prepare edildi. Preparasyon aşamasında her eğeden sonra kök kanalları 2 mL \%5.25'lik Na$\mathrm{OCl}$ ile yıkandı. Preparasyon sonrasında kanallar $10 \mathrm{ml}$ distile su ile yıkandı ve kağıt koniler (Paper Point, DiaPro ISO .06, Diadent Group Int., Chungcheongbuk-do, Kore) kullanılarak kurutuldu. Kanallar AH-26 kanal patı (Dentsply De Trey, Konstanz, Almanya) ve F3 numaralı Protaper guta perka konlar (Dia-Pro ISO.06, Diadent Group Int., Chungcheongbuk-do, Kore) ile dolduruldu ve kanal ağızları geçici dolgu materyali olarak kompozit rezin (Clearfil Majesty Esthetics, Kuraray, Osaka Japonya) ile kapatıldı. Her bir diş $1.5 \times 1.5 \times 2.5 \mathrm{~cm}$ boyutlarındaki prizma kalıplar içerisindeki polimetilmetakrilata (Paladent RR, Heraeus Kulzer, Hanau, Almanya) gömüldü. Mekanik aşındırıcılar kullanılarak dişlerin koronal kısımları açığa çıkartıldı ve geçici doldu maddesi uzaklaştırılarak, RelyX Fiber Post sisteminin 3 nolu 
post yuvası hazırlama frezi (RelyX Fiber Post Drill Refill, 3M ESPE, Seefeld, Almanya) ile $11 \mathrm{~mm}$ uzunluğunda post yuvaları hazırlandı. Hazırlanan post yuvaları $2 \mathrm{~mL}$ $\% 5.25 \mathrm{NaOCl}$ ile, ardından $10 \mathrm{~mL}$ distile su ile yıkandı ve kağıt koniler kullanılarak kurutuldu. Hazırlanan örnekler rastgele 4 gruba ayrıldı.

Kullanılacak olan fiber postlar (RelyX Fiber Post, 3M ESPE, Seefeld, Almanya) $11 \mathrm{~mm}$ olacak şekilde işaretlendi ve karbon separe ile kesildi. Postların yüzeyleri alkol ile temizlenip, hava ile kurutuldu.

Grup 1 ve Grup 2'de kendinden bağlanabilen rezin siman RelyX Unicem (3M ESPE, St. Paul, MN, ABD), üretici talimatları doğrultusunda karıştırıldı ve post boşluğunun apikalinden koronaline doğru yavaşça dolduruldu. Hazırlanan post siman ile doldurulmuş post boşluğuna yerleştirilip LED ışık cihazı ile (Elipar Free Light 2, 3M ESPE, St. Paul, MN, ABD) ile 40 sn boyunca polimerize edildi. Grup 2'de kendinden bağlanabilen rezin siman yerleştirilmeden önce tek aşamalı bağlayıcı sistem olan Adper Easy One (3M ESPE, St. Paul, MN, $A B D)$ post boşluğuna üretici talimatları doğrultusunda uygulanarak 10 sn LED ışık cihazı ile polimerize edildi.

Postların yapıştırılmasında Grup 3'te kendinden bağlanabilen rezin siman Clearfil SA Cement (Kuraray, Osaka, Japonya) ve Grup 4'te kendinden bağlanabilen rezin siman yerleştirilmeden önce tek aşamalı bağlayıcı sistem olan Clearfil S3 Bond (Kuraray) Grup 1 ve Grup 2'deki işlemlere benzer şekilde üretici talimatlarına göre uygulandı. Clearfil SA Cement (Kuraray) LED ışık cihazı (Elipar Free Light 2) ile 20 sn boyunca Clearfil S3 Bond (Kuraray) 10 sn boyunca üretici talimatlarına göre polimerize edildi.

Her bir grup için 20 örnek olacak şekilde toplam 80 örnek \%100 nemli ortamda $37^{\circ} \mathrm{C}$ 'lik etüve yerleştirildi. 24 saat sonra her gruptan rastgele 10 örnek seçildi. Her bir diş kökünün postu içeren kısmının koronal, orta ve apikal bölümlerinin her birinden 2'şer adet olmak üzere, $1 \mathrm{~mm}$ kalınlıkta transversal yönde toplam 6 kesit su soğutması altında yüksek hızda dönen alet (Mecatome T 201A, Presi, Brié-et-Angonnes, Fransa) yardımıyla alındı.

\section{Push-out bağlanma dayanım testi}

Kesitler universal test cihazına (Autograph AG-10kNIS, Shimadzu Co., Kyoto Japonya) yerleştirilerek, cihazın post çapına uygun olan ucu $1 \mathrm{~mm} / \mathrm{dk}$ hızda ilerleyecek şekilde, post kök yüzeyinden ayrılıncaya kadar post yüzeyine kuvvet uygulandı. Bağlanma dayanım direnç değerleri mega paskala (MPa) çevrilerek her bir örnek için kaydedildi. Aynı işlemler kalan 10 örnekte 1 ay sonunda tekrar edildi.

\section{İstatistiksel değerlendirme}

İstatistiksel değerlendirmeler SPSS 15.0 (SPSS, Inc., Chicago, IL, ABD) programında \%5 istatistiksel anlamlılık düzeyinde yapıldı. Elde edilen verilerin karşılaştırılmasında tek yönlü varyans analizi kullanıldı.
Çoklu karşılaştırmalar Tukey HSD test yöntemi ile değerlendirildi $(p=0.05)$. 24 saat ve 1 aylık sonuçların karşılaştırılmasında bağımsız değişkenler t-testi kullanıldı $(p=0.05)$.

\section{BULGULAR}

Grupların 24 saat ve 1 ay sonundaki bölgelere göre bağlanma dayanım ortalama ve standart sapma değerleri (Ort_SD; MPa) Tablo 2'de verildi.

\section{4 saatlik ölçümler}

Her bir grupta 24 saatlik ölçümlerde, kesitler bölgesel olarak ayrılmadığında, yapılan varyans analizi sonuçlarına göre en yüksek bağlanma dayanım değeri Grup 2'de (13.66 $\pm 3.86 \mathrm{MPa})$, en düşük bağlanma dayanımı değeri ise Grup 3’te $(2.83 \pm 2.08 \mathrm{MPa})$ görüldü. Tek yönlü varyans analizi (ANOVA) testi ile gruplar arasında istatistiksel olarak anlamlı fark olduğu bulundu $(p<0.05)$. Bunun üzerine yapılan post hoc Tukey HSD testine göre farkın Grup 1 ile Grup $2(p=0.000)$, Grup 3 ile Grup 4 ( $p=0.000)$, Grup 1 ile Grup $3(p=0.000)$, Grup 2 ile Grup $4(p=0.000)$ arasında olduğu görüldü.

Her grup koronal, orta ve apikal bölgelere göre kendi içerisinde değerlendirildiğinde:

Grup 1 için orta bölge ile apikal bölge ve orta bölge ile koronal bölge arasında istatistiksel olarak anlamlı fark bulunmazken (sırasıyla $p=0.245$ ve $p=0.109$ ), apikal ile koronal bölge arasında anlamlı fark bulundu ( $p=0.002)$. Grup 2'de koronal, orta ve apikal bölgeler arasında fark bulunmadı ( $p>0.05$ ). Grup 3 için tüm bölgeler arasında anlamlı fark bulundu $(p<0.05)$. Grup 4'te orta ve koronal bölge arasında anlamlı fark bulunmazken ( $p=0.140)$, koronal ve apikal arasında ve orta ve apikal bölge arasında anlamlı fark bulundu $(\mathrm{p}<0.05)$.

Bölgelere göre gruplar birbirleriyle karşılaştırıldı-

Tablo 2. Grupların ( $n=20) 24$ saat ve 1 ay sonundaki bölgelere göre bağlanma dayanım ortalama ve standart sapma değerleri (Ort $\pm S D$; $\mathrm{MPa}$; 24 saatlik ve 1 aylık ortalama değerler her bölge için $1 \mathrm{~mm}$ 'lik 20'şer adet kesitten ölçüm yapılarak elde edilmiştir).

\begin{tabular}{cccc}
\hline Gruplar & Bölge & 24 saat & 1 ay \\
& & & \\
\hline & Koronal & $10.00 \pm 3.18$ & $8.97 \pm 3.50$ \\
Grup 1 $(\mathbf{n = 2 0 )}$ & Orta & $7.86 \pm 3.29$ & $8.08 \pm 4.20$ \\
(RelyX Unicem) & Apikal & $6.17 \pm 3.40$ & $7.43 \pm 4.58$ \\
& Toplam & $8.01 \pm 3.60$ & $8.16 \pm 4.10$ \\
& Koronal & $13.87 \pm 4.14$ & $11.84 \pm 3.39$ \\
Grup 2 $(\mathbf{n}=\mathbf{2 0})$ & Orta & $14.47 \pm 3.89$ & $9.49 \pm 3.54$ \\
(RelyX Unicem +Adper & Apikal & $12.64 \pm 3.51$ & $7.97 \pm 4.73$ \\
Easy One) & Toplam & $13.66 \pm 3.86$ & $9.80 \pm 4.17$ \\
& Koronal & $4.79 \pm 1.98$ & $5.47 \pm 3.43$ \\
Grup 3 (n=20) & Orta & $2.48 \pm 1.10$ & $3.32 \pm 2.98$ \\
(Clearfil SA Cement) & Apikal & $1.04 \pm 0.85$ & $1.53 \pm 0.93$ \\
& Toplam & $2.83 \pm 2.08$ & $3.33 \pm 3.03$ \\
\hline Grup 4 $(\mathbf{n}=\mathbf{2 0})$ & Koronal & $11.95 \pm 5.41$ & $10.12 \pm 3.84$ \\
bond) & Orta & $8.92 \pm 5.43$ & $6.79 \pm 3.71$ \\
& Apikal & $3.81 \pm 3.92$ & $5.28 \pm 4.09$ \\
(Clearfil SA Cement+S3 & Toplam & $8.23 \pm 5.94$ & $7.34 \pm 4.31$ \\
\hline
\end{tabular}


ğında, koronal bölgede Grup 2'nin bağlanma dayanı$\mathrm{m}$ I değerleri Grup 4 ile benzer bulunurken $(\mathrm{p}=0.407)$, Grup 3'ün koronal bölge bağlanma dayanımı değerleri diğer tüm gruplardan anlamlı derecede düşük bulundu $(\mathrm{p}=0.000)$.

Orta ve apikal bölge için Grup 2'nin bağlanma dayanımı değerleri diğer tüm gruplardan anlamlı derecede daha yüksek( $p=0.000)$, Grup 3'ün bağlanma dayanımı değerleri diğer tüm gruplardan anlamlı derecede daha düşük bulundu $(p<0.05)$.

\section{1 aylık ölçümler}

Her bir grupta 1 aylık ölçümlerde, kesitler bölgesel olarak ayrılmadığında, yapılan varyans analizi sonuçlarına göre en yüksek bağlanma dayanım değeri Grup 2'de $(9.80 \pm 4.17 \mathrm{MPa})$ ve en düşük bağlanma dayanım değeri Grup 3'te (3.33 $\pm 3.03 \mathrm{MPa})$ gözlendi. Tek yönlü varyans analizi (ANOVA) testi ile gruplar arasında istatistiksel olarak anlamlı fark olduğu bulundu $(p<0.05)$. Bunun üzerine yapılan post hoc Tukey HSD testine göre farkın Grup 1 ile Grup $3(p=0.000)$, Grup 2 ile Grup $4(p=0.002)$, Grup 3 ile Grup $4(p=0.000)$ arasında olduğu, Grup 1 ve Grup 2 arasında istatistiksel olarak anlamlı fark olmadığı $(p=0.077)$ görüldü.

Her grup koronal orta ve apikal bölgelere göre kendi içerisinde değerlendirildiğinde:

Grup 1 için her üç bölge birbiriyle kıyaslandığında anlamlı bir fark bulundu $(p<0.05)$. Grup 2 için sadece apikal ile koronal bölgeler arasında anlamlı fark bulundu ( $p=0.009)$. Grup 3 ve Grup 4'te orta ve apikal bölge benzer sonuçlar verirken (sırasıyla $p=0.089$ ve $p=0.447$ ), her iki grupta da koronal bölge diğer bölgelere göre daha yüksek bağlanma dayanımı değerleri gösterdi $(p<0.05)$.

Bölgelere göre gruplar birbirleriyle karşılaştırıldığında, koronal, orta ve apikal bölgelerde Grup 3'ün diğer tüm gruplardan anlamlı derecede daha düşük bağlanma dayanımı değerleri gösterdiği bulundu $(p<0.05)$. Her üç bölgede de diğer gruplar arasında anlamlı bir istatistiksel farklılık gözlenmedi ( $p>0.05$ ).

\section{4 saatlik ve 1 aylık ölçümlerin karşılaştırılması}

Grup 1, Grup 3 ve Grup 4'ün 24 saatlik ve 1 aylık bağlanma dayanım değerleri bağımsız değişkenler t-testi ile karşılaştırıldığında istatistiksel bir fark bulunmazken ( $p>0.05)$, Grup 2'de 1 ay sonunda bağlanma dayanım değerlerinde anlamlı bir düşüş meydana geldi $(p=0.000)$.

Grup 1, Grup 3 ve Grup 4'te koronal, orta ve apikal bölgeler 24 saatlik ve 1 aylık dönemlerdeki bağlanma dayanımları açısından kıyaslandığında, hiçbir bölgede istatistiksel olarak anlamlı fark bulunmadı ( $p>0.05)$. Grup 2'de ise koronal bölgede 24 saat ve 1 aylık bağlanma dayanım değerleri benzerlik gösterirken $(p=0.099)$, orta ve apikal bölgelerde bağlanma dayanım değerlerinin 1 aylık dönem sonunda anlamlı derecede düşmüş olduğu görüldü (sırasıyla $p=0.000$ ve $p=0.001$ ).

\section{TARTIŞMA}

İdeal post materyali, diş yapısının doğal esneme hareketine benzer yapıda bir elastikiyet gösterebilmelidir. 8-11 $^{-1}$

Klinikte gözlemlenen başarısızlıkların çoğu, metal postların stres dağılımındaki düzensizliklere bağlı olarak oluşan stres yoğunlaşma alanlarının, diş ile postkor yapıda bulunan mikro çatlakları büyüterek zamanla dentin kırıklarına yol açması ile oluşmaktadır. ${ }^{12,13} 1990$ yılından itibaren farklı fiber yapılarla güçlendirilen kompozit postlar geliştirilmeye başlanmıştır. ${ }^{14}$ Günümüzde çeşitli fiberlerle güçlendirilmiş kompozit postların, dentine yakın fiziksel özellikler taşıdıkları, fonksiyonel kuvvetlere yeterli direnç sağladıkları ve bu yükler altındaki fonksiyon esnasında kalan diş dokusuna daha az zarar verdikleri, ${ }^{15,16}$ korozyon dirençleri, estetik olmaları, endodontik tekrarlayan tedavi gereksinimlerinde daha kolay sökülebilir olmaları ve tek bir seansta uygulanabilmeleri gibi avantajları ile ön plana çıkmışlardır. ${ }^{9} \mathrm{Bu}$ nedenle çalışmamızda, elastiklik modülü dentine yakın olan, oklüzal yükleri kök dentinine daha orantılı bir şekilde dağıtarak daha az kök kırığına neden olduğu in vitro çalışmalarda gösterilmiş, ışık geçirgenliği olan mikropöröz yüzey özelliklerine sahip cam ile güçlendirilmiş kompozit fiber post olan Rely $\mathrm{X}$ fiber post kullanıldı.

Başarılı bir fiber post-kor restorasyonu, post materyali ve kök dentin yüzeyi arasında kuvvetli bir bağlantı oluşmasını sağlayan simantasyon tekniğine bağlıdır. Bu bağlantıyı sağlayan güncel rezin simanlar post uygulanmadan önce dentin yüzeyine yapılan ön uygulamayaklaşımlarınagörefarklılıklargöstermektedir. Fiber postlar, dual cure rezin simanların üç aşamalı tüm pürüzlendirmeli (etch\&rinse), kendinden pürüzlendirmeli (self etch) ajan içeren iki aşamalı ve pürüzlendirme ve bağlanma özelliklerini tek aşamada birleştiren bağlayıcı sistemlerden biri ile birlikte kullanılması ile simante edilebilirler. ${ }^{17}$ Post simantasyonunda kullanılan farklı bağlanma yaklaşımlarının birbirlerine olan üstünlükleri konusunda literatürde çok sayıda ve birbirleriyle çelişen sonuçlar ${ }^{17}$ ve kök kanalı içerisinde bağlanma ile ilgili birçok problemden dolayı hangi bağlayıcı kombinasyonunun seçileceği konusunda tartışmalar mevcuttur. Dentin yüzeyinde herhangi bir ön işlem yapılmasını gerektirmeyen kendinden bağlanabilen rezin simanlar, yüksek bağlantı gücünün basit ve standart bir yaklaşımla elde edilebilmesini sağlar. ${ }^{18}$ Rezin simanlar; kimyasal, ışıkla ve hem ışık uygulaması hem de kimyasal yolla polimerize olanlar olmak üzere üç farklı polimerizasyon sistemine sahiptir. Kimyasal olarak polimerize olan sistemlerin çalışma sürelerinin kısıtlı olması, ışık ile aktive olan sistemlerin kanalın apikal bölgelerinde aktivasyonunun tam olarak sağlanamaması gibi dezavantajlarından dolayı çalışmamızda, hem ışık uygulaması hem de kimyasal yolla polimerize olabilen dual cure rezin simanlar tercih edildi. Çalışmamızda 2 farklı kendinden bağlanabilen rezin simanın tek başlarına ve uygun bağlayıcı ajan ile birlikte kullanımlarının post-kök dentin yüzeyi bağlantısı 
açısından karşılaştırılması ve kombine kullanımın bu bağlantının kuvvetlenmesine katkısı olup olmayacağının araştırılması amaçlandı.

Diş kökünün farklı bölgelerinde dentin tübüllerinin sayı ve dağılımlarının anatomik olarak farklılıklar göstermesi bağlayıcı tekniklerle direkt olarak dentine bağlanan restorasyonların başarısını etkilemektedir. ${ }^{18}$ Post tipinden bağımsız olarak en yüksek bağlanma dayanımının koronal, en düşük bağlanma dayanımının ise apikal bölgede olduğu bildirilmiştir. ${ }^{18-22} \mathrm{Bu}$ durumun nedenleri arasında post boşluğunun apikal kısmına ulaşma güçlüğü, simanın apikal bölgeye tam olarak uygulanmasındaki zorluklar ve bunlara bağlı mikro boşlukların oluşması ya da o bölgede kök kanal dolgu materyali ve kanal patı artıklarının kalmış olması 18,19,21,23${ }^{26}$, dentin tübül sayısının apikal bölgelere gidildikçe azalması $^{27}$, koronal bölgeye bağlayıcı ajanların daha kolay uygulanması ve polimerizasyon için kullanılan ışık kaynaklarının apikal bölgeye göre bu bölgede daha etkili olabilmesi ${ }^{28}$ olarak özetlenebilir. Post restorasyonlarında başarısızlığa yol açabilen bu faktörlerin kökün farklı bölgelerinde değerlendirilmesinin büyük önem taşıması açısından çalışmamızda farklı bağlayıcı yaklaşımların bağlanma dayanım değerleri, kökün farklı bölgelerinde incelendi.

Bağlanma dayanımı değerlerini ölçmek için pek çok farklı yöntem kullanılmış olmakla birlikte, pushout testinde dentin bağlayıcı yüzeyine paralel kuvvet uygulanması nedeniyle geleneksel makaslama, gerilim ve mikrogerilim testlerine göre daha uygun ve güvenilir bir yöntem olduğu ve kök kanal sisteminde oluşan düşük bağlanma dayanımı değerlerini ölçmeye olanak sağladığı bildirilmiştir. ${ }^{29}$ İncelenecek disklerin 1 mm'den daha kalın olması, materyallerin sürtünme yüzeyinin artmasına bağlı olarak bağlanma dayanımı değerlerinin olduğundan fazla ölçülmesine neden olduğu için, ${ }^{29}$ push-out testinde literatürde de önerildiği gibi disk kalınlıkları $1 \mathrm{~mm}$ olarak hazırlandı.

Bağlanma dayanımı değerlendirmeleri genellikle restoratif işlemlerden 24 saat sonra yapılmaktadır. ${ }^{19,30-32}$

Birçok çalışmada belirtildiği gibi uzun dönem klinik kullanım (restorasyonun yaşı) restorasyonların başarı oranlarını anlamlı oranda düşürmektedir. ${ }^{33}$ Çalışmamızda bağlanma dayanım değerlerinin zaman içerisinde azalma gösterip göstermediğini değerlendirmek amacıyla post simantasyon işlemleri tamamlandıktan 24 saat ve 1 ay sonrasında ölçümler gerçekleştirildi.

Simantasyon sonrası ilk 24 saatlik ölçüm sonuçlarına bakıldığında bağlanma dayanımının en yüksek Grup 2'de, en düşük olarak ise Grup 3'te olduğu görüldü. Bu sonuç birinci ay ölçümlerde de gözlendi. Kısa dönem sonuçlar değerlendirildiğinde benzer materyal ve testlerin kullanıldığı bir çalışmada Kıvanç ve ark. ${ }^{33}$ çalışmamıza benzer kendinden bağlanabilen rezin siman olan RelyX Unicem'in Adper Bond ile kullanımının, tek başına kullanımına göre bağlanma dayanımı değerlerini anlamlı derecede arttırdığını bildirmiştir. Bu sonuç yazarlar tarafından kendinden bağlanabilen rezin simanlardan önce dentin yüzeyine yapılan uygulamanın smear tabakasını etkileyerek dentin demineralizasyonunu arttırıp mikromekanik bağlanmaya katkıda bulunması ile açıklanmıştır. Diğer taraftan Erdemirveark. ${ }^{18}$ 'nın yaptıkları birçalışmada aynı materyallerin kombine kullanımı, tek başına kendinden bağlanabilen RelyX Unicem simana göre daha düşük bağlanma dayanımı göstermiştir. Ancak, Erdemir ve ark. ${ }^{18}$ bu çalışmada siman kullanımından önce dentin yüzeylerine \%37'lik fosforik asit uygulamışlardır.

Bitter ve ark. ${ }^{25}$ çalışmamızla paralel olarak RelyX Unicem simanının bağlanma dayanımı değerlerini Clearfil SA simana göre anlamlı derecede üstün bulmuş ve bu sonucu Clearfil SA grubunda bağlantı ara yüzeyindeki mikroboşluk oluşumuna bağlı olarak sızıntı görülmesi ile açıklamışlardır. Özcan ve ark. ${ }^{34}$ ise Clearfil SA simanın tek başına RelyX Unicem'e göre anlamlı derecede daha dayanıklı olduğunu bildirmişlerdir. Bu çalışmada Clearfil SA siman RelyX Unicem'den faklı olarak enjeksiyon tekniği ile kök kanalına uygulanmış ve böylece uygun baz-katalizör oranı elde edilerek kanal içerisinde mikro hava kabarcığı oluşumu riski azaltılmıştır.

Leme vearkadaşlarının ${ }^{35}$ 1. ve9. ay değerlendirmeleri yaptıkları çalışmalarında, tek başına RelyX Unicem siman kullanılan grupta zaman içerisinde bağlantı kuvveti belirgin şekilde azalmıştır. Bu sonuçlar zaman içerisinde post-dentin veya post-bağlayıcı bölgelerinde bağlantının zayıflayabileceği beklendiğinden tutarlı ve çalışmamızın sonuçları ile uyumludur.

Çalışmamızda incelenen kök bölgeleri dikkate alındığında 24 saat ölçümü için koronal, orta ve apikal bölgelerin hepsinde RelyX Unicem rezin simanın Adper Easy One ile kombine kullanıldığı Grup 2 diğer gruplara kıyasla anlamlı derecede yüksek bağlanma dayanımı değerleri gösterdi. Bu grubu yine her üç bölge için de benzer dayanıklılık gösteren Grup 1 ve Grup 4 takip etti ve her iki grup da Grup 3'e göre anlamlı derecede daha yüksek bağlanma dayanımı değerleri gösterdi. Bu sonuç RelyX Unicem simanın tek başına ve Adper Easy One ile kombine kullanımının karşılaştıııldığı Kıvanç ve arkadaşlarının ${ }^{33} 1$ haftalık kısa dönem sonuçları ile uyumludur, ancak aynı araştırmada 3 aylık uzun dönem sonuçlara göre Rely $X$ Unicem simanın diğer adezivlerle kombine kullanılması daha yüksek bağlanma dayanımı değerleri elde edilmesine neden olmuştur. Çalışmamızda kısa dönem sonuçlarda bağlanma dayanımı direnci her üç bölge için de Grup 2'yi desteklese de, 1. ay sonunda Grup 1, Grup 2 ve Grup 4 arasında istatistiksel olarak anlamlı bir fark görülmedi. Bununla birlikte bu üç tedavi grubu kökün tüm bölgelerinde Grup 3’ten daha dayanıklı bulundu. Leme ve ark. ${ }^{35}$ RelyX Unicem'in tek başına kullanımının özellikle apikal bölgede 1. aya göre 9. ayda dayanımının anlamlı derecede düştüğünü bildirmişlerdir.

Tedavi gruplarını dikkate almaksızın 24 saat ölçümünde en düşük bağlanma dayanımının literatüre 
paralel olarak apikal bölgede olduğu tespit edildi, bunu sırasıyla orta ve koronal bölge izledi. ${ }^{18,19,21,22,33,34,36}$ Birinci ay ölçümünde ise apikal ve orta bölgede bağlanma dayanımı değerleri yakın ve koronal bölgeye göre anlamlı derecede düşük bulundu. ${ }^{33,35} \mathrm{Her}$ iki ölçüm döneminde de bağlantının daha düşük bulunduğu apikal ve orta bölgelerde RelyX Unicem'in Adper Easy One ile birlikte kullanımı daha iyi bağlantı dayanım değerleri göstermiştir.

\section{Sonuç}

$\mathrm{Bu}$ in vitro çalışma koşullarında, kendinden bağlanabiIen rezin simanların, uygun bir bağlayıcı ile kullanımlarının bağlanma dayanımlarını arttırdığı söylenebilir. Bu durumda çalışmanın sıfır hipotezi reddedilmiştir. Kökün post içeren kısmı bölgesel olarak incelendiğinde en düşük bağlantı dayanım değerleri postun apikal 1/3'lük kısmında izlenirken, en yüksek bağlanma dayanım değerleri koronal 1/3'lük kısımda izlenmektedir.

\section{TEŞEKKÜR VE ANMA}

Bu araştırma Gazi Üniversitesi Bilimsel Araştırma Projeleri Birimi tarafından desteklenmiştir.

Çıkar çatışması: Yazarlar bu çalışmayla ilgili herhangi bir çıkar çatışmalarının bulunmadığını bildirmişlerdir.

\section{KAYNAKLAR}

1. Perdigão J, Gomes G, Augusto V. The effect of dowel space on the bond strengths of fiber posts. J Prosthodont 2007;16:154-64.

2. Huang TJ, Schilder H, Nathanson D. Effects of moisture content and endodontic treatment on some mechanical properties of human dentin. J Endod 1992;18:209-15.

3. Sedgley $\mathrm{CM}$, Messer $\mathrm{HH}$. Are endodontically treated teeth more brittle? J Endod 1992;18:332-5.

4.Sorensen JA, Martinoff JT. Intracoronal reinforcement and coronal coverage: a study of endodontically treated teeth. $\mathrm{J}$ Prosthet Dent 1984;51:780-4.

5. Goracci C, Ferrari M. Current perspectives on post systems: a literature review. Aust Dent J 2011;56:77-83.

6. Boschian Pest L, Cavalli G, Bertani P, Gagliani M. Adhesive postendodontic restorations with fiber posts: push-out tests and SEM observations. Dent Mater 2002;18:596-602.

7. Rosentritt M, Behr M, Lang R, Handel G. Influence of cement type on the marginal adaptation of all-ceramic MOD inlays. Dent Mater 2004;20:463-9.

8. Fernandes AS, Shetty S, Coutinho I. Factors determining post selection: a literature review. J Prosthet Dent 2003;90:556-62.

9. Lamichhane A, Xu C, Zhang FQ. Dental fiber-post resin base material: a review. J Adv Prosthodont 2014;6:60-5.

10. Chieruzzi M, Pagano S, Pennacchi M, Lombardo G, D'Errico P, Kenny JM. Compressive and flexural behaviour of fibre reinforced endodontic posts. J Dent 2012;40:968-78.

11. Ricketts DN, Tait CM, Higgins AJ. Post and core systems, refinements to tooth preparation and cementation. Br Dent J 2005;198:53341.

12. Coelho CS, Biffi JC, Silva GR, Abrahão A, Campos RE, Soares CJ. Finite element analysis of weakened roots restored with composite resin and posts. Dent Mater J 2009;28:671-8.
13. da Silva NR, Raposo LH, Versluis A, Fernandes-Neto AJ, Soares CJ. The effect of post, core, crown type, and ferrule presence on the biomechanical behavior of endodontically treated bovine anterior teeth. J Prosthet Dent 2010;104:306-17.

14. Duret B, Reynaud M, Duret F. New concept of coronoradicular reconstruction: the Composipost. Chir Dent Fr 1990;60:131-41.

15. Ferrari M, Vichi A, García-Godoy F. Clinical evaluation of fiberreinforced epoxy resin posts and cast post and cores. Am J Dent 2000;13:15B-18B.

16. Novais VR, Quagliatto PS, Bona AD, Correr-Sobrinho L, Soares CJ. Flexural modulus, flexural strength, and stiffness of fiber-reinforced posts. Indian J Dent Res 2009; 20:277-81.

17. Skupien JA, Sarkis-Onofre R, Cenci MS, Moraes RR, Pereira-Cenci T. A systematic review of factors associated with the retention of glass fiber posts. Braz Oral Res 2015;29:1-8.

18. Erdemir U, Mumcu E, Topcu FT, Yildiz E, Yamanel K, Akyol M. Micro push-out bond strengths of 2 fiber post types luted using different adhesive strategies. Oral Surg Oral Med Oral Pathol Oral Radiol Endod 2010;110:534-44.

19. Bouillaguet S, Troesch S, Wataha JC, Krejci I, Meyer JM, Pashley $\mathrm{DH}$. Microtensile bond strength between adhesive cements and root canal dentin. Dent Mater 2003;19:199-205.

20. Montanari M, Prati C, Piana G. Differential hydrolytic degradation of dentin bonds when luting carbon fiber posts to the root canal. Med Oral Patol Oral Cir Bucal 2011;16:e411-7.

21. Mallmann A, Jacques LB, Valandro LF, Mathias $P$, Muench $A$. Microtensile bond strength of light- and self-cured adhesive systems to intraradicular dentin using a translucent fiber post. Oper Dent 2005;30:500-6.

22. Lopes GC, Ballarin A, Baratieri LN. Bond strength and fracture analysis between resin cements and root canal dentin. Aust Endod $\mathrm{J}$ 2012;38:14-20.

23. Ryou H, Romberg E, Pashley DH, Tay FR, Arola D. Importance of age on the dynamic mechanical behavior of intertubular and peritubular dentin. J Mech Behav Biomed Mater 2015;42:229-42.

24. Muniz L, Mathias P. The influence of sodium hypochlorite and root canal sealers on post retention in different dentin regions. Oper Dent 2005;30:533-9.

25. Bitter K, Meyer-Lueckel H, Priehn K, Kanjuparambil JP, Neumann $\mathrm{K}$, Kielbassa AM. Effects of luting agent and thermocycling on bond strengths to root canal dentine. Int Endod J 2006;39:809-18.

26. Bolhuis $P$, de Gee A, Feilzer A. The influence of fatigue loading on the quality of the cement layer and retention strength of carbon fiber post-resin composite core restorations. Oper Dent 2005;30:220-7.

27. Ferrari M, Mannocci F, Vichi A, Cagidiaco MC, Mjör IA. Bonding to root canal: structural characteristics of the substrate. Am J Dent 2000;13:255-60.

28. Ho YC, Lai YL, Chou IC, Yang SF, Lee SY. Effects of light attenuation by fibre posts on polymerization of a dual-cured resin cement and microleakage of post-restored teeth. J Dent 2011;39:309-15.

29. Goracci C, Tavares AU, Fabianelli A, Monticelli F, Raffaelli O, Cardoso PC, et al. The adhesion between fiber posts and root canal walls: comparison between microtensile and push-out bond strength measurements. Eur J Oral Sci 2004;112:353-61.

30. Forough Reyhani M, Ghasemi N, Rahimi S, Milani AS, Omrani E. Effect of Different Endodontic Sealers on the Pushout Bond Strength of Fiber Posts. Iran Endod J 2016;11:119-23.

31. Goracci C, Fabianelli A, Sadek FT, Papacchini F, Tay FR, Ferrari $M$. The contribution of friction to the dislocation resistance of bonded fiber posts. J Endod 2005;31:608-12.

32. Victorino KR, Kuga MC, Duarte MA, Cavenago BC, Só MV, Pereira JR. The effects of chlorhexidine and ethanol on pushout bond strength of fiber posts. J Conserv Dent 2016;19:96-100.

33. Helvacıoğlu Kıvanç B, Deniz Arısu H, Uçtaşlı MB, Okay TC. The effect of different adhesive system applications on push-out bond strengths of glass fiber posts. J Adv Prosthodont 2013;5:305-11. 
34. Ozcan S, Aktuna S, Nayır Y, Yaman S, Bala O. Push-out bond strength of fiber posts luted using different adhesive resin cements. J Rest Dent 2013;1:75-80

35. Leme AA, Coutinho M, Insaurralde AF, Scaffa PM, da Silva LM The influence of time and cement type on push-out bond strength of fiber posts to root dentin. Oper Dent 2011;36:643-8.

36. Kurtz JS, Perdigão J, Geraldeli S, Hodges JS, Bowles WR Bond strengths of tooth-colored posts, effect of sealer, dentin adhesive, and root region. Am J Dent 2003;16:31A-36A

\section{Effect of post space treatment with adhesives on the push-out bond strength of fiber posts luted with self-adhesive resin cements}

\section{Abstract} \\ OBJECTIVE: The aim of this study was to evaluate the push- \\ out bond strength of fiber posts used in the restoration of \\ endodontically-treated teeth with extreme material loss, \\ luted with two different self-adhesive resin cements alone \\ or with the combination of an adhesive. \\ Materials and Method: The post spaces of 80 extracted \\ mandibular first premolar roots were prepared and \\ divided into 4 experimental groups according to fiber \\ post (RelyX Fiber Post) luting material. Group 1 was luted
}

with RelyX Unicem, Group 2 was luted with RelyX Unicem + Adper Easy One, Group 3 was luted with Clearfil SA Cement, and Group 4 was luted with Clearfil SA Cement + S3 Bond. After $24 \mathrm{~h}$ and 1 month, horizontal sections of $1 \mathrm{~mm}$ thickness were made from the coronal, middle and apical root parts of the fiber posts, and push-out tests were performed. Groups were compared by using one way analysis of variance (ANOVA) and Tukey's HSD post hoc tests and storage periods were compared by using independent samples t-test $(\alpha=0.05)$.

RESULTS: For both evaluation time periods, RelyX Unicem + Adper Easy One showed the highest bond strength. Regarding the $24 \mathrm{~h}$ period, the lowest bond strength values were found for the apical sections followed by middle and coronal sections. One month results revealed similar bond strength values for the middle and apical sections $(p>0.05)$ which were significantly lower than the values found for the coronal sections $(p<0.05)$. RelyX Unicem + Adper Easy One exhibited greater push-out bonding strength compared to other groups in the middle and apical sections $(p<0.05)$.

CONCLUSION: According to the results of this in vitro study it can be concluded that, using an adhesive system in combination with a self-adhesive resin cement during post cementation may improve the bond strength.

KEYWORDS: Bonding agents, dentin; post technique; resin cements 